\title{
Three-Dimensional Large-Pore Covalent Organic Framework with stp Topology
}

\author{
Hui Li,${ }^{\S, \dagger}$ Jiehua Ding,,${ }^{\S} \dagger$ Xinyu Guan,${ }^{\dagger}$ Fengqian Chen,${ }^{\dagger}$ Cuiyan Li,${ }^{\dagger}$ Liangkui Zhu, ${ }^{\dagger}$ Ming Xue, ${ }^{\dagger}$ \\ Yushan Yan, ${ }^{\dagger}$ Valentin Valtchev, ${ }^{\dagger, \|}$ Shilun Qiu, ${ }^{\dagger}$ and Qianrong Fang ${ }^{* \dagger}$ \\ ${ }^{\dagger}$ State Key Laboratory of Inorganic Synthesis and Preparative Chemistry, Jilin University, Changchun 130012, P. R. China \\ ${ }^{\ddagger}$ Department of Chemical and Biomolecular Engineering, Center for Catalytic Science and Technology, University of Dela- \\ ware, Newark, DE 19716, USA
}

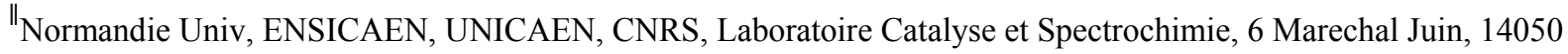
Caen, France

Supporting Information Placeholder

\begin{abstract}
Three-dimensional (3D) covalent organic frameworks (COFs) are excellent porous crystalline polymers for numerous applications, but their building units and topological nets have been limited. Herein we report the first 3D large-pore COF with stp topology constructed with a 6-connected triptycene-based monomer. The new COF (termed JUC-564) has high surface area (up to $3300 \mathrm{~m}^{2} \mathrm{~g}^{-1}$ ), the largest pore (43 $\AA$ ) among 3D COFs, and record-breaking low density in crystalline materials $\left(0.108 \mathrm{~g} \mathrm{~cm}^{-3}\right)$. The large pore size of JUC-564 is confirmed by the incorporation of a large protein. This study expands the structural varieties of 3D COFs as well as their applications for adsorption and separation of large biological molecules.
\end{abstract}

Covalent organic frameworks (COFs), ${ }^{1-5}$ a remarkable class of organic porous crystalline materials with high surface areas and promising stabilities, have attracted wide interests in varied fields including gas adsorption and separation, ${ }^{6-9}$ catalysis, ${ }^{10-15}$ optoelectronics, ${ }^{16-20}$ and some others. ${ }^{21-26}$ Over the past decade, most researches have been focused on two-dimensional (2D) COFs with eclipsed AA stacking modes. ${ }^{1-4}$ Three-dimensional (3D) COFs are considered as ideal platforms for abundant uses because of their interconnected channels, superior surface areas, and fully exposed active sites. ${ }^{27-36}$ However, only few topologies are available for 3D COFs so far, such as ctn, bor, dia, and pts, and almost all of them are based on tetrahedral building blocks, which have extremely limited the structural diversities of 3D COFs. ${ }^{5}$ Interestingly, Wang, Feng and co-workers synthesized the first 3D anionic COFs with rra topology, CD-COFs, in which each boron atom is joined to four $\gamma$-cyclodextrin struts, and each $\gamma$-cyclodextrin is connected to eight boron atoms. ${ }^{37}$ Thomas, Roeser and coworkers have recently demonstrated a novel $3 \mathrm{D}$ anionic silicate COF adopting a two-fold interpenetrated srs-c topology by reticulating dianionic hexacoordinate $\left[\mathrm{SiO}_{6}\right]^{2-}$ nodes with 3connected triphenylene building blocks. ${ }^{38}$ In principle, the employment of new building units, such as 6-connected monomer with $D_{3 \mathrm{~h}}$ geometry, can establish novel architectures in 3D COFs; however, its realization has remained an enormous challenge.

Herein, we for the first time reported a 3D triptycene-based COF with large pores and stp topology. This novel COF, termed JUC564 (JUC $=$ Jilin University China), was constructed from a stereoscopic 6-connected triptycene-based building unit, 2,3,6,7,14,15-hexa(4'-formylphenyl)triptycene (HFPTP). As a result, JUC-564 showed high surface area $\left(>3300 \mathrm{~m}^{2} \mathrm{~g}^{-1}\right)$, the largest pore (43 $\AA$ ) among 3D COFs, and the lowest density among all crystalline materials $\left(0.108 \mathrm{~g} \mathrm{~cm}^{-3}\right)$. Moreover, due to the presence of large pores, JUC-564 showed a favorable adsorption of a large protein with suitable dimensions.

Structural identification is one of major roadblocks for developing 3D frameworks with new topologies. Different from other crystalline porous materials, such as aluminosilicate molecular sieves ${ }^{39}$ and metal-organic frameworks (MOFs), ${ }^{40,41}$ single crystals are not common in COFs and their crystal structures are mostly obtained through powder X-ray diffraction (PXRD) patterns along with structural simulation. Usually, more than one possible topology is available for combinations of multiple building block geometries. After investigating RCSR database carefully, we fortunately found that only definite stp topology is available for $[6+4]\left(3 \mathrm{D}-D_{3 h}+2 \mathrm{D}-D_{2 h}\right)$ nets (Scheme 1), facilitating the structural determination of the target products. ${ }^{42}$ To implement this strategy, we firstly designed a 6-connected 3D- $D_{3 h}$ building block, HFPTP, based on a triptycene moiety with a link angle of $60^{\circ}$ (Scheme 1a). Condensation of HFPTP and a synergistic 4-connected $2 \mathrm{D}-D_{2 h}$ monomer with a link angle of $120^{\circ}$ (1,3,6,8-tetra(4-aminophenyl)pyrene, TAPPy, Scheme 1b) leads to an expanded [6+4] connected network (JUC-564, Scheme 1c and 1d). To the best of our knowledge, JUC-564 represents the first COF with a 6-connected $3 \mathrm{D}-D_{3 h}$ building block and a stp net.

The synthesis of JUC-564 was carried out through traditional solvothermal approach by suspending HFPTP and TAPPy in a mixed solvent of mesitylene and dioxane with the presence of $6 \mathrm{M}$ acetic acid followed by heating at $120{ }^{\circ} \mathrm{C}$ for 3 days. Complementary methods have been employed for detailed structural determination and characterization. Scanning electron microscopy (SEM, Figure S1) and transmission electron microscopy (TEM, Figure S2) images revealed isometric microcrystals. Fourier transform infrared (FT-IR) spectrum exhibited a new adsorption corresponding to the characteristic of the $\mathrm{C}=\mathrm{N}$ bond at $1628 \mathrm{~cm}^{-1}$. The concomitant reducing of the $\mathrm{C}=\mathrm{O}$ stretching $\left(1700 \mathrm{~cm}^{-1}\right.$ for HFTPT) and N-H stretching $\left(3312 \mathrm{~cm}^{-1}\right.$ 


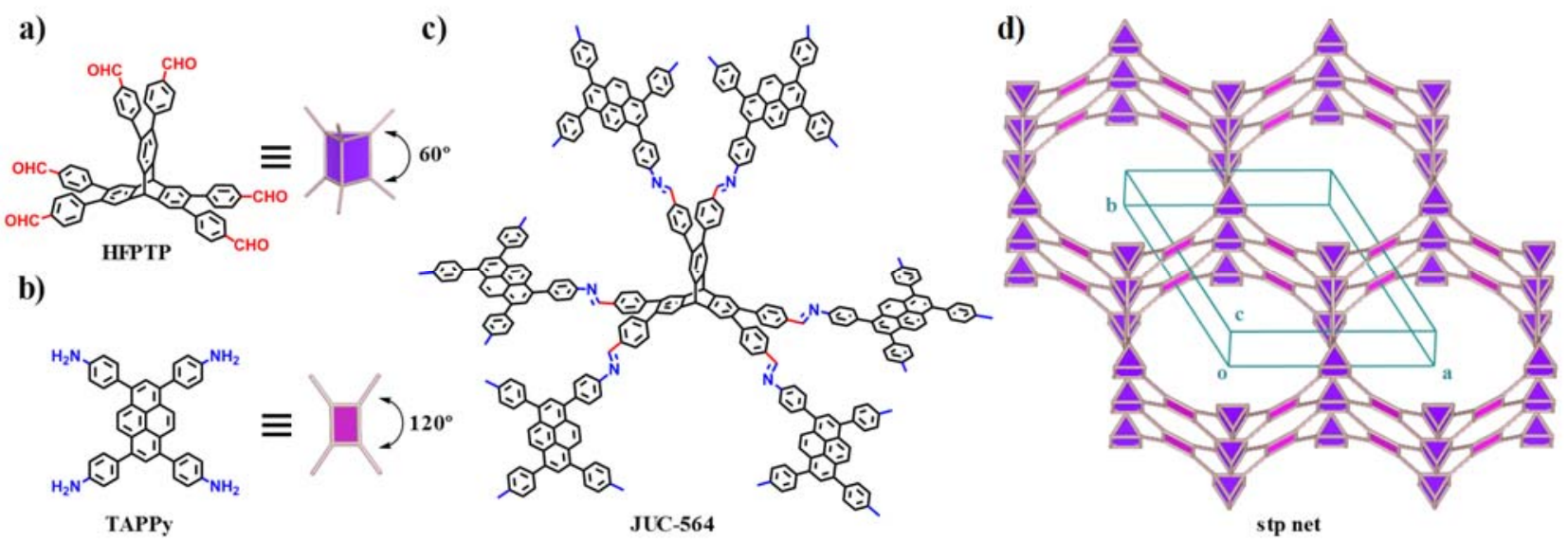

${ }^{a}$ Molecular structures of HFPTP (a) as a 6-connected 3D- $D_{3 h}$ core building block and TAPPy (b) as a synergistic 4-connected 2D- $D_{2 h}$ monomer. A novel 3D COF, JUC-564 (c), constructed from the condensation reaction of HFPTP and TAPPy. A expanded stp net (d) for JUC-564.

for TATPy) confirmed the transformation of aldehyde and amine groups (Figure $\mathrm{S} 3$ ). The solid-state ${ }^{13} \mathrm{C}$ cross-polarization magicangle-spinning (CP/MAS) NMR spectroscopy further verified the presence of imine groups by the peak at $157 \mathrm{ppm}$ (Figure S4). High thermal stability $\left(\sim 450{ }^{\circ} \mathrm{C}\right)$ was observed by thermogravimetric analysis (TGA, Figure S5).

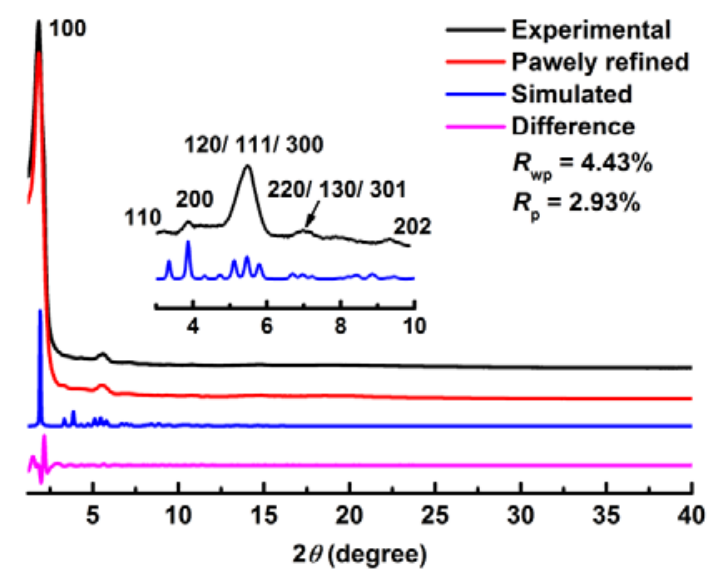

Figure 1. PXRD pattern of JUC-564.

The crystal structure was resolved by PXRD measurements in conjunction with structural simulations (Figure 1). After a geometrical energy minimization of JUC-564 by the Materials Studio software package on the basis of stp net, ${ }^{43}$ the simulated PXRD pattern was in good agreement with the experimental one. Furthermore, the full profile pattern matching (Pawley) refinement was conducted based on experimental peaks at 1.93, 3.34, 3.87, 5.47, 6.96, and $9.46^{\circ}$ corresponding to (100), (110), (200), (120) (or (111) and (300)), 220 (or (130) and (301)) and (202) Bragg peaks of space group $P 6 / \mathrm{m}$ (No. 175). The refinement results can match well with the observed ones with negligible difference and good agreement factors $(R \mathrm{p}=2.93 \%$ and $\omega \mathrm{Rp}=4.43 \%)$. The refinement results yield a unit cell with parameters of $a=b=$ $52.8112 \AA, c=20.4914 \AA, \alpha=\beta=90^{\circ}$, and $\gamma=120^{\circ}$, which are very similar to those of suggested model $(a=b=52.7911 \AA, c=$

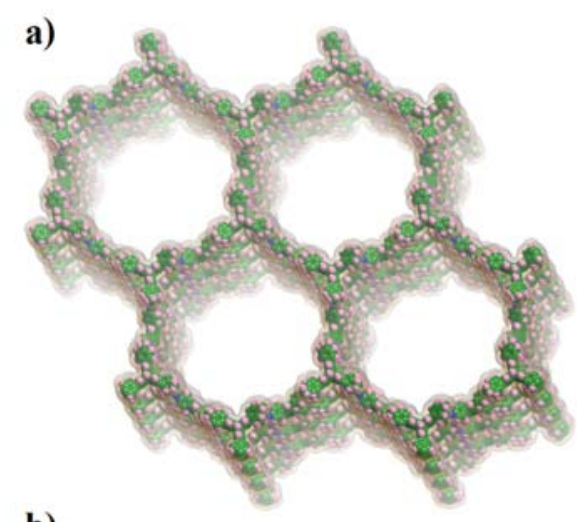

b)

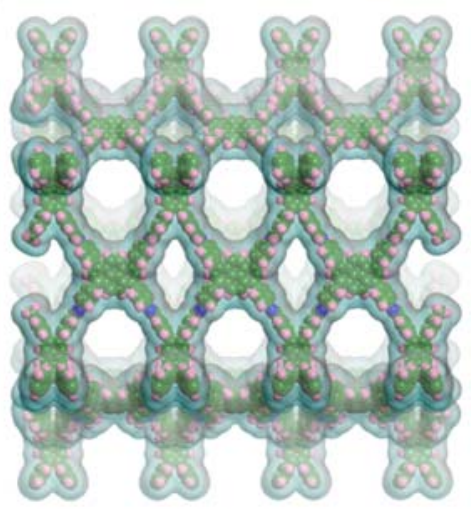

Figure 2. Extended structure of JUC-564 viewed along $c$ axis (a) and $a$ or $b$ axis (b). C, green; H, pink, N, blue.

$20.4794 \AA, \alpha=\beta=90^{\circ}$, and $\gamma=120^{\circ}$ ). In light of these results, JUC564 is proposed to have the expected $3 \mathrm{D}$ framework with pore sizes of $14 \AA$ along $a$ or $b$ axis and $43 \AA$ along $c$ axis (Figure 2). Notably, benefiting from its highly void framework and light constitutional elements, JUC-564 has a calculated density of $0.108 \mathrm{~g} \mathrm{~cm}^{-3}$, which is the lowest reported for any crystalline material known to date, such as MOFs $\left(0.22 \mathrm{~g} \mathrm{~cm}^{-3}\right.$ for MOF-200, ${ }^{44} 0.195 \mathrm{~g} \mathrm{~cm}^{-3}$ for 
IRMOF-74-XI, ${ }^{45}$ and $0.124 \mathrm{~g} \mathrm{~cm}^{-3}$ for NU-1301 $\left.{ }^{46}\right)$ and COFs $(0.19$ $\mathrm{g} \mathrm{cm}^{-3}$ for JUC- $518,{ }^{20} 0.17 \mathrm{~g} \mathrm{~cm}^{-3}$ for COF- $108,{ }^{27}$ and $0.13 \mathrm{~g} \mathrm{~cm}^{-3}$ for DBA-3D-COF $1^{47}$ ).

To investigate the porosity of JUC-564, gas sorption study of $\mathrm{N}_{2}$ was conducted at $77 \mathrm{~K}$. As shown in Figure 3a, JUC-564 exhibited typical reversible type IV isotherms, which is one of the main characteristics of mesoporous materials. The surface area was calculated to be $3383 \mathrm{~m}^{2} \mathrm{~g}^{-1}$ using the Brunauer-Emmett-Teller (BET) model (Figure S6). Pore size distribution calculated by nonlocal density functional theory (NLDFT) illustrated two kinds of pores with sizes of $15 \AA$ and $41 \AA$ (Figure $3 \mathrm{~b}$ ), which are in good agreement with those of the proposed structure (14 $\AA$ and $43 \AA$ ). Remarkably, the largest pore size of JUC-564 (43 $\AA$ ) is far superior to that of other reported 3D COFs (Table S1), such as $13.5 \AA$ for COF-102, ${ }^{27} 13.6 \AA$ for DL-COF- $1,{ }^{33} 15.4 \AA$ for JUC- $518,{ }^{20}$ and 28 $\AA$ for DBA-3D-COF $1{ }^{47}$ Furthermore, its BET surface area (3383 $\left.\mathrm{m}^{2} \mathrm{~g}^{-1}\right)$ is much higher than that of other 3D imine-based COFs (Figure 4 and Table S2), such as $1360 \mathrm{~m}^{2} \mathrm{~g}^{-1}$ for COF-300, ${ }^{48} 1513$ $\mathrm{m}^{2} \mathrm{~g}^{-1}$ for JUC-508, ${ }^{15} 2020 \mathrm{~m}^{2} \mathrm{~g}^{-1}$ for LZU-111, ${ }^{31}$ and $3023 \mathrm{~m}^{2} \mathrm{~g}^{-1}$ for JUC-552. ${ }^{36}$
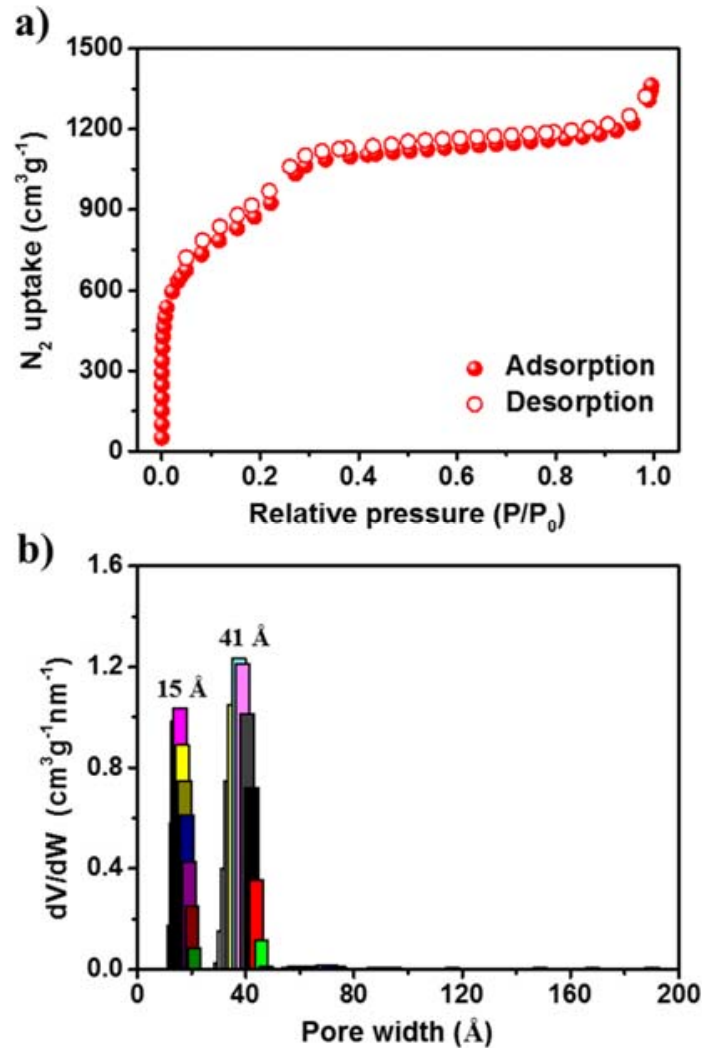

Figure 3. (a) $\mathrm{N}_{2}$ adsorption-desorption isotherm at $77 \mathrm{~K}$ and (b) pore-size distribution for JUC-564.

To further define the structure and large channels of JUC-564, incorporation of large biomolecules with suitable dimensions as probes was explored (Figures S7-12). The uptake ability of JUC564 for myoglobin $(\mathrm{Mb} \text {, about } 21 \AA \times 35 \AA \times 44 \AA)^{49}$ was confirmed by UV-vis spectrum, which proves the existence of the wide channel ( $43 \AA$ ) in JUC-564. For comparison, no observable adsorption of $\mathrm{Mb}$ in the microporous $\mathrm{COF}-320$ took place due to its smaller pore size $(\sim 12 \AA)$.

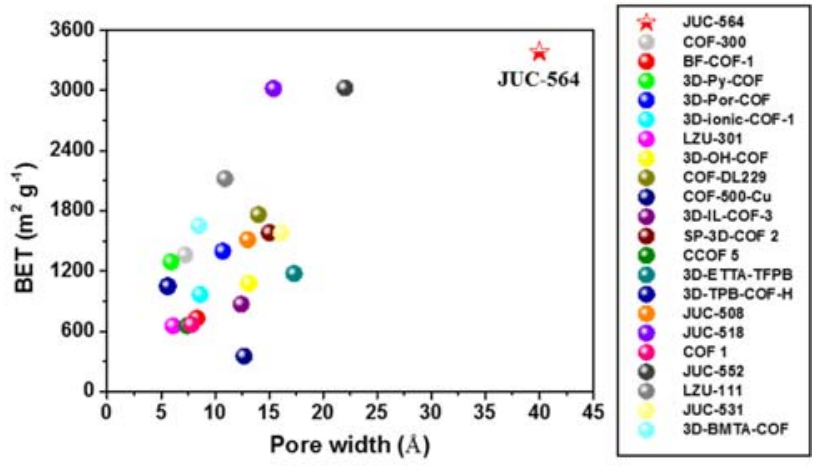

Figure 4. A summary of BET surface areas versus pore sizes in 3D imine-based COFs.

In summary, we have developed a large-pore 3D COF with novel stp topology utilizing a rare 6-connected $D_{3 \mathrm{~h}}$ node based on triptycene. JUC-564 exhibited interconnected channel systems with high surface areas $\left(3383 \mathrm{~m}^{2} \mathrm{~g}^{-1}\right)$, ultra-large channels (up to 43 $\AA$ ), record-breaking low density $\left(0.108 \mathrm{~g} \mathrm{~cm}^{-3}\right)$, and positive uptake of a large protein molecule. This work not only opens a door to enrich 3D structures of COFs but also promotes new applications of 3D COFs in adsorption of large biological molecules.

\section{Supporting Information}

Methods and synthetic procedures, SEM, FTIR, solid state ${ }^{13} \mathrm{C}$ NMR, TGA, BET plot, and unit cell parameters. This material is available free of charge via the internet at http://pubs.acs.org.

\section{AUTHOR INFORMATION}

\section{Corresponding Author}

*qrfang@jlu.edu.cn

\section{Author Contributions}

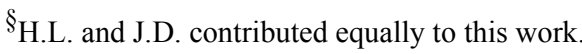

Notes

The authors declare no competing financial interests.

\section{ACKNOWLEDGMENT}

This work was supported by National Natural Science Foundation of China (21571079, 21621001, 21390394, 21571076, and 21571078), "111" project (BP0719036 and B17020), and the program for JLU Science and Technology Innovative Research Team. Q.F. and V.V. acknowledge the Thousand Talents program (China). V.V., Q.F. and S.Q. acknowledge the collaboration in the framework of China-French joint laboratory "Zeolites".

\section{REFERENCES}

(1) Côté, A. P.; Benin, A. I.; Ockwig, N. W.; O'Keeffe, M.; Matzger, A. J.; Yaghi, O. M. Porous, Crystalline, Covalent Organic Frameworks. Science 2005, 310, 1166.

(2) Colson, J. W.; Woll, A. R.; Mukherjee, A. Levendorf, M. P.; Spitler, E. L.; Shields, V. B.; Spencer, M. G.; Park, J.; Dichtel, W. R. Science 2011, 332, 228.

(3) Feng, X.; Ding, X. S.; Jiang, D. L. Covalent Organic Frameworks. Chem. Soc. Rev. 2012, 41, 6010.

(4) Ding, S. Y.; Wang, W. Covalent Organic Frameworks (COFs): from Design to Applications. Chem. Soc. Rev. 2013, 42, 548. 
(5) Guan, X. Y.; Chen, F. Q.; Fang, Q. R.; Qiu, S. L. Design and Applications of Three Dimensional Covalent Organic Frameworks. Chem. Soc. Rev. 2020, 49, 1357.

(6) Kuhn, P.; Antonietti, M.; Thomas, A. Porous, Covalent TriazineBased Frameworks Prepared by Ionothermal Synthesis. Angew. Chem. Int. Ed. 2008, 47, 3450.

(7) Han, S. S.; Furukawa, H.; Yaghi, O. M.; Goddard, W. A., III Covalent Organic Frameworks as Exceptional Hydrogen Storage Materials. J. Am. Chem. Soc. 2008, 130, 11580.

(8) Fang, Q. R.; Zhuang, Z. B.; Gu, S.; Kaspar, R. B.; Zheng, J.; Wang, J. H.; Qiu, S. L.; Yan, Y. S. Designed synthesis of largepore crystalline polyimide covalent organic frameworks. Nat. Commun. 2014, 5, 4503.

(9) Wang, S.; Wang, Q.; Shao, P.; Han, Y.; Gao, X.; Ma, L.; Yuan, S.; Ma, X.; Zhou, J.; Feng, X.; Wang, B. Exfoliation of Covalent Organic Frameworks into Few-layer Redox-Active Nanosheets as Cathode Materials for Lithium-Ion Batteries. J. Am. Chem. Soc. 2017, 139, 4258.

(10) Ding, S. Y.; Gao, J.; Wang, Q.; Zhang, Y.; Song, W. G.; Su, C. Y.; Wang, W. Construction of Covalent Organic Framework for Catalysis: Pd/COF-LZU1 in Suzuki-Miyaura Coupling Reaction. $J$. Am. Chem. Soc. 2011, 133, 19816.

(11) Fang, Q. R.; Gu, S.; Zheng, J.; Zhuang, Z. B.; Qiu, S. L.; Yan, Y. S. 3D Microporous Base-Functionalized Covalent Organic Frameworks for Size-Selective Catalysis. Angew. Chem. Int. Ed. 2014, 53, 2878

(12) Vyas, V. S.; Haase, F.; Stegbauer, L.; Savasci, G.; Podjaski, F.; Ochsenfeld, C.; Lotsch, B. V. A Tunable Azine Covalent Organic Framework Platform for Visible Light-Induced Hydrogen Generation. Nat. Commun. 2015, 6, 8508 .

(13) Wang, X.; Han, X.; Zhang, J.; Wu, X.; Liu, Y.; Cui, Y. Homochiral 2D Porous Covalent Organic Frameworks for Heterogeneous Asymmetric Catalysis. J. Am. Chem. Soc. 2016, 138,12332

(14) Sun, Q.; Aguila, B.; Perman, J.; Nguyen, N.; Ma, S. Q. Flexibility Matters: Cooperative Active Sites in Covalent Organic Framework and Threaded Ionic Polymer. J. Am. Chem. Soc. 2016, 138,15790

(15) Yan, S. C.; Guan, X. Y.; Li, H.; Li, D. H.; Xue, M.; Yan, Y. S.; Valtchev, V.; Qiu, S. L.; Fang, Q. R. Three-dimensional Salphen-based Covalent-Organic Frameworks as Catalytic Antioxidants. J. Am. Chem. Soc. 2019, 141, 2920.

(16) Wan, S.; Guo, J.; Kim, J.; Ihee, H.; Jiang, D. A Belt-Shaped, Blue Luminescent, and Semiconducting Covalent Organic Framework. Angew. Chem. Int. Ed. 2008, 47, 8826.

(17) Dogru, M.; Handloser, M.; Auras, F.; Kunz, T.; Medina, D.; Hartschuh, A.; Knochel, P.; Bein, T. A Photoconductive Thienothiophene-Based Covalent Organic Framework Showing Charge Transfer Towards Included Fullerene. Angew. Chem. Int. Ed. 2013, 52, 2920.

(18) Bertrand, G. H. V.; Michaelis, V. K.; Ong, T. C.; Griffin, R. G.; Dinca, M. Thiophene-Based Covalent Organic Frameworks. Proc. Natl. Acad. Sci. U. S. A. 2013, 110, 4923.

(19) Du, Y.; Yang, H.; Whiteley, J. M.; Wan, S.; Jin, Y.; Lee, S. H.; Zhang, W. Ionic Covalent Organic Frameworks with Spiroborate Linkage. Angew. Chem. Int. Ed. 2016, 55, 1737.

(20) Li, H.; Chang, J. H.; Li, S. S.; Guan, X. Y.; Li, D. H.; Li, C. Y.; Tang, L. X.; Xue, M.; Yan, Y. S.; Valtchev, V.; Qiu, S. L.; Fang, Q. R. Three-Dimensional Tetrathiafulvalene-Based Covalent Organic Frameworks for Tunable Electrical Conductivity. J. Am. Chem. Soc. 2019, 141, 13324.

(21) Chandra, S.; Kundu, T.; Kandambeth, S.; BabaRao, R.; Marathe, M. Y.; Kunjir, S. M.; Banerjee, R. Phosphoric Acid Loaded Azo $(-\mathrm{N}=\mathrm{N}-)$ Based Covalent Organic Framework for Proton Conduction. J. Am. Chem. Soc. 2014, 136, 6570.
(22) Zhou, T. Y.; Xu, S. Q.; Wen, Q.; Pang, Z. F.; Zhao, X. OneStep Construction of Two Different Kinds of Pores in a 2D Covalent Organic Framework. J. Am. Chem. Soc. 2014, 136, 15885.

(23) Lu, Q. Y.; Ma, Y. C.; Li, H.; Guan, X. Y.; Yusran, Y.; Xue, M.; Fang, Q. R.; Yan, Y. S.; Qiu, S. L.; Valtchev, V. Postsynthetic Functionalization of Three-Dimensional Covalent Organic Frameworks for Selective Extraction of Lanthanide Ions. Angew. Chem. Int. Ed. 2018, 57, 6042.

(24) Guan, X. Y.; Li, H.; Ma, Y. C.; Xue, M.; Fang, Q. R.; Yan, Y. S.; Valtchev, V.; Qiu, S. L. Chemically Stable PolyaryletherBased Covalent Organic Frameworks. Nat. Chem. 2019, 11, 587.

(25) Guo, Z. B.; Zhang, Y. Y.; Dong, Y.; Li, J.; Li, S. W.; Shao, P. P.; Feng, X.; Wang, B. Fast Ion Transport Pathway Provided by Polyethylene Glycol Confined in Covalent Organic Frameworks. $J$. Am. Chem. Soc. 2019, 141, 1923.

(26) Li, D. H.; Li, C. Y.; Zhang, L. J.; Li, H.; Zhu, L. K.; Yang, D. J.; Fang, Q. R.; Qiu, S. L.; Yao, X. D. Metal-Free ThiopheneSulfur Covalent Organic Frameworks: Precise and Controllable Synthesis of Catalytic Active Sites for Oxygen Reduction. J. Am. Chem. Soc. 2020, 142, 8104.

(27) El-Kaderi, H. M.; Hunt, J. R.; Mendoza-Cortes, J. L.; Côté, A. P.; Taylor, R. E.; O’Keeffe, M.; Yaghi, O. M. Designed Synthesis of 3D Covalent Organic Frameworks. Science 2007, 316, 268.

(28) Beaudoin, D.; Maris, T.; Wuest, J. D. Constructing Monocrystalline Covalent Organic Networks by Polymerization. Nat. Chem. 2013, 5, 830.

(29) Lin, G. Q.; Ding, H. M.; Yuan, D. Q.; Wang, B. S.; Wang, C. A Pyrene-Based, Fluorescent Three-Dimensional Covalent Organic Framework. J. Am. Chem. Soc. 2016, 138, 3302.

(30) Lan, Y. S.; Han, X. H.; Tong, M. M.; Huang, H. L.; Yang, Q. Y.; Liu, D. H.; Zhao, X.; Zhong, C. L. Materials genomics methods for high-throughput construction of COFs and targeted synthesis. Nat. Commun. 2018, 9, 5274.

(31) Ma, T. Q.; Kapustin, E. A.; Yin, S. X.; Liang, L.; Zhou, Z. Y.; Niu, J.; Li, L. H.; Wang, Y. Y.; Su, J.; Li, J.; Wang, X. G.; Wang, W. D.; Wang, W.; Sun, J. L.; Yaghi, O. M. Single-Crystal X-Ray Diffraction Structures of Covalent Organic Frameworks. Science 2018, 361, 48.

(32) Fang, Q. R.; Wang, J. H.; Su, S.; Kaspar, R. B.; Zhuang, Z. B.; Zheng, J.; Guo, H. X.; Qiu, S. L.; Yan, Y. S. J. Am. Chem. Soc. 2015, 137, 8352 .

(33) Li, H.; Pan, Q. Y.; Ma, Y. C.; Guan, X. Y.; Xue, M.; Fang, Q. R.; Yan, Y. S.; Valtchev, V.; Qiu, S. L. Three-Dimensional Covalent Organic Frameworks with Dual Linkages for Bifunctional Cascade Catalysis. J. Am. Chem. Soc. 2016, 138, 14783.

(34) Li, Z. L.; Li, H.; Guan, X. Y.; Tang, J. J.; Yusran, Y.; Li, Z.; Xue, M.; Fang, Q. R.; Yan, Y. S.; Valtchev, V.; Qiu, S. L. ThreeDimensional Ionic Covalent Organic Frameworks for Rapid, Reversible, and Selective Ion Exchange. J. Am. Chem. Soc. 2017, $139,17771$.

(35) Guan, X. Y.; Ma, Y. C.; Li, H.; Yusran, Y.; Xue, M.; Fang, Q. R.; Yan, Y. S.; Valtchev, V.; Qiu, S. L. Fast, Ambient Temperature and Pressure Ionothermal Synthesis of ThreeDimensional Covalent Organic Frameworks. J. Am. Chem. Soc. 2018, 140, 4494.

(36) Wang, Y. J.; Liu, Y. Z.; Li, H.; Guan, X. Y.; Xue, M.; Yan, Y. S.; Valtchev, V.; Qiu, S. L.; Fang, Q. R. Three-Dimensional Mesoporous Covalent Organic Frameworks through Steric Hindrance Engineering. J. Am. Chem. Soc. 2020, 142, 3736.

(37) Zhang, Y. Y.; Duan, J. Y.; Ma, D.; Li, P. F.; Li, S. W.; Li, H. W.; Zhou, J. W.; Ma, X. J.; Feng, X.; Wang, B. ThreeDimensional Anionic Cyclodextrin-Based Covalent Organic Frameworks. Angew. Chem. Int. Ed. 2017, 56, 16313. 
(38) Yahiaoui, O.; Fitch, A. N.; Hoffmann, F.; Fröba, M.; Thomas, A.; Roeser, J. 3D Anionic Silicate Covalent Organic Framework with srs Topology. J. Am. Chem. Soc. 2018, 140, 5330.

(39) Valtchev, V.; Majano, G.; Mintova, S.; Perez-Ramirez, J. Tailored Crystalline Microporous Materials by Post-Synthesis Modification. Chem. Soc. Rev. 2013, 42, 263.

(40) Zhou, H. C.; Long, J. R.; Yaghi, O. M. Introduction to Metal-Organic Frameworks. Chem. Rev. 2012, 112, 673

(41) Qiu, S. L.; Xue, M.; Zhu, G. S. Metal-Organic Framework Membranes: from Synthesis to Separation Application. Chem. Soc. Rev. 2014, 43, 6116.

(42) http://rcsr.net/nets.

(43) Materials Studio ver. 7.0; Accelrys Inc.: San Diego, CA.

(44) Furukawa, H.; Ko, N.; Go, Y. B.; Aratani, N.; Choi, S. B.; Choi, E.; Yazaydin, A. Ö; Snurr, R. Q.; O'Keeffe, M.; Kim, J.; Yaghi, O. M. Ultrahigh Porosity in Metal-Organic Frameworks. Science 2010, 329, 424.

(45) Deng, H.; Grunder, S.; Cordova, K. E.; Valente, Cory, Furukawa, H.; Hmadeh, M.; Gándara, F.; Whalley, A. C.; Liu, Z.;
Asahina, S.; Kazumori, H.; O'Keeffe, M.; Terasaki, O.; Stoddart, J. F.; Yaghi, O. M. Large-Pore Apertures in a Series of Metal-Organic Frameworks. Science 2012, 336, 1018.

(46) Li, P.; Vermeulen, N. A.; Malliakas, C. D.; GómezGualdrón, D. A.; Howarth A. J.; Mehdi, B. L.; Dohnalkova, A.; Browning, N. D.; O'Keeffe, M.; Farha, O. K. Bottom-up construction of a superstructure in a porous uranium-organic crystal. Science 2017, 356, 624 .

(47) Baldwin, L. A.; Crowe, J. W.; Pyles, D. A.; McGrier P. L. Metalation of a Mesoporous Three-Dimensional Covalent Organic Framework. J. Am. Chem. Soc. 2016, 138, 15134.

(48) Uribe-Romo, F. J.; Hunt, J. R.; Furukawa, H.; Klöck, C. O'Keeffe, M.; Yaghi, O. M. A Crystalline Imine-Linked 3D Porous Covalent Organic Framework. J. Am. Chem. Soc. 2009, 131, 4570.

(49) Chen, Y.; Lykourinou, V.; Hoang, T.; Ming, L. J.; Ma, S. Q. Size-Selective Biocatalysis of Myoglobin Immobilized into a Mesoporous Metal-Organic Framework with Hierarchical Pore Sizes. Inorg. Chem. 2012, 51, 9156. 
TOC Graphic:

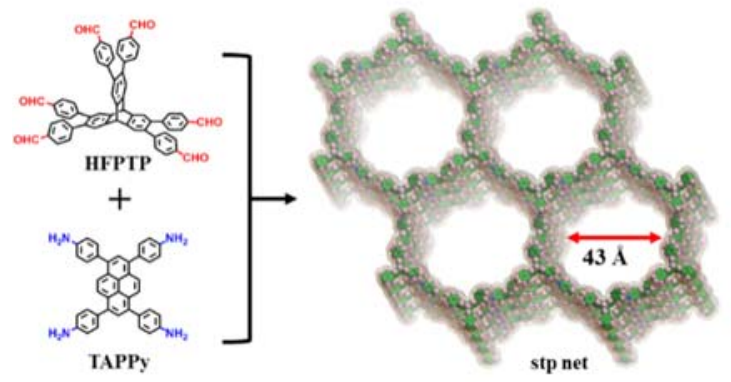

